\title{
Garment Single-piece Flow Production Based on Template Sewing Technique
}

\author{
Jishu zhang and Peiguo Wang \\ School of Art \& Clothing Engineering \\ Changshu Institute of Technology \\ Changshu, China \\ zhangjishu@163.com, wang_peiguo@126.com
}

\begin{abstract}
Lean and Agile Manufacturing has been a hot issue in garment manufacturing in China nowadays. In this paper, a new garment manufacturing mode was presented named as garment single-piece flow production based on template sewing technique. The differences between garment single piece flow production codes under the condition of traditional sewing equipment and assisted by template are analyzed. Six key factors for the effective operation of garment piece flow production modes based on template sewing technology are expounded emphatically, which includes production preparation process, process analysis, template design, GST analysis, man-machine position arrangement and staff participating consciousness. It also provides reference for the transformation and upgrading of garment manufacturing enterprises.
\end{abstract}

Keywords-template technology; single-piece flow; garment production mode.

\section{INTRODUCTION}

In recent years, the eastern coastal developed regions of China have generally been in shortage of labor, land and environmental resources, which render the total factor costs of the textile and clothing industry on the rise. How to improve production efficiency and lower production cost has been urgent key issues for the clothing manufacturers. So lots of garment enterprises are in great demand of production of automation, digitalization and intelligentization, and some of them have adopted advanced manufacturing technology and production mode, such as the garment template technique [1], one-piece production in lean production [2] and so on, to improve the efficiency of the clothing production.

\section{OVERVIEW OF TEMPLATE SEWING TECHNIQUES AND SINGLE- PIECE LINE PRODUCTION MODE}

\section{A. TEMPLATE SEWING TECHNIQUES}

Template sewing technique is a new technology based on principles of garment manufacturing, mechanical engineering and garment CAD digitization, including opening slot in the mold material, installing template roller and needle plate in the sewing machine, and sewing on the set template path [3]. In 1979, template technology was introduced into the Chinese mainland market, but was limited to be applied in a small number of processes. After 2000, more people in Guangzhou began to have contact with clothing template process, thus template technology facilities were substantially improved, and then application of clothing template technology to the apparel production was recognized. After the 2008 economic crisis, the study of template technology has a groundbreaking breakthrough and the application of this technology started from local use to a large area of application. Apparel template technology developed from original hand-made template according to the pattern, ordinary sewing with template sewing equipment to chiller cutting template of laser tube line with apparel CAD design, and stitcher sewing with semiautomatic template. Now it is in the stage of cutting templates with automatic profile cutting machine of special designed software of clothing template and automatic sewing templates [4]. With the growing popularity of clothing template technology and indepth research, its scope and applicability will be more comprehensive.

\section{B. SINGLE-PIECE LINE PRODUCTION MODE}

Single piece production mode is under the guidance of the concept of lean production, on the basis of traditional packing assembly line to improve production processes and to achieve production mode of single piece process [5]. It emphasizes synchronization and balance of flow in the production process, by organic combination of people, machine, material and time to make profits in maximization; it reduces time of production preparation, by total productive maintenance to eliminate downtime and reduce waste, effectively improving the production activities; by a person responsible for multiple machines, and production equipment installed automatic detection device to improve labor utilization directly. In order to make single-piece pipelining form play higher efficiency, many advanced aided manufacturing techniques and equipment have been applied to garment production, such as template sewing technology, conveyor belt transmission box equipment, intelligent suspension system, RFID system[6] and so on. The production pattern of single-piece flow based on template sewing technique is one of the forms.

\section{KEY TECHNOLOGIES OF GARMENT SINGLE-PIECE FLOW BASED ON TEMPLATE SEWING TECHNIQUE}

Garment single-piece pipelining model based on template sewing technique combine the technology of garment 
$\mathrm{CAD} / \mathrm{CAM}$ with clothing process engineering, process, on the analytic bases of process and motion of garment production making the corresponding template of garment sewing unit, and applying to single-piece pipelining with two distinctive characteristics: standard rhythm and one work in progress. Compared with single-piece flow mode with conventional sewing machine, garment single-piece flow based on template sewing technique has great differences such as less pipelined operator, lower employee skill level requirements, easy to implement standard operation, lower operation time of the tedious repetitive process and so on.

Its key technology to achieve high efficiency includes the following aspects: production preparation process, process analysis and integration, template design, GST analysis, human-machine-station arrangement and full participation consciousness.

\section{A. Production preparation process}

Production preparation process is the high-efficient start of garment single-piece flow production mode based on template technology. The process needs to be carried out in accordance with the company's production schedule in the first three days of the start of the big goods in each style. Firstly IE department host a production preparation meeting, which needs department of garment template technology, department of garment pattern, department of garment sample, head of the production line, department of garment TPE and department of garment IE to participate in, to discuss the clothing style of to be started to produce. Garment sample department and garment pattern sector put forward suggestions on the type of problems of garment pattern; Garment TPE and IE departments investigate with clothing sample department whether every sewing process in line fits for assembly line production and has the possibility of process optimization; Garment TPE and garment template technology sectors, combining the process analysis table provided by garment IE department with the process tables of requirements and technical difficulty provided by garment sample department, analyze whether the template fixture in the corresponding parts of the application is reasonable and whether its design is reasonable, as well as how to make the production line more convenient for operators; production line leader make some optimization suggestions for the station arrangement of garment IE department combined with the actual situation of the production line workers.

Through the production preparation process, the best clothing production design and production aided design could be achieved, the standard operation action, the correct placement of parts, delivery time of parts timely supplying, reasonable machine layout and sequence and qualified standards could be determined, and workers would be ensured to complete the best products with the least amount of movement, the most simple and convenient operation, the safest and the most comfortable state. It can be said that production preparation process is an important guarantee for the efficient operation of garment single-piece flow production mode based on template technology.

\section{B. Process analysis and integration}

Different from the single-piece flow production with traditional sewing equipment, the new garment single-piece flow production mode based on template technology, in process analysis, compile procedure analysis table suitable for assembly line production, not in accordance with the production process flow chart provided by clothing sample sector, but according to the application of template technology and considering which parts should use template fixture and which parts should not. For example, the part needing to point position and to fix seam could be preferred to use the template fixture operations. The sewing of the corresponding part after pointing position or fixing seam is generally required to be placed in the same station, which is because the next sewing after position or set sewing is continuous action. If they are distributed to different station, the extra waste of repeated actions of taking, holding, snatching, placing and moving etc. will undoubtedly be caused. So it can reduce processes of some station and the probability of the occurrence of the bottleneck process. However, in process analysis, the use of template fixture is not the more the better. In the model of garment single-piece flow production based on template technology, it also should be considered that the motion range of some operation actions could be enlarged because of using templates and result in unnecessary movement waste, as it is better to use ordinary sewing for some straight arc seam..

\section{Sewing template design}

Sewing template design is another important technological process immediately following process analysis. In designing clothing template, in spite of considering how to reduce operational difficulties for the employees and ensure quality standards, more importantly, it should also be considered that a one-piece garment flow forms of homework standard beats and one work in progress to make the production lines smooth and to avoid the negative phenomena of some vacant seats waiting while others overloaded. For instance, almost all processes of the certain body parts of garment can be integrated into a template for one person to complete, which can save a lot of stations in the arrangement of production assembly line. But if the template integrates too many processes, the time to complete the task of the big body template will be far beyond the standard beat, which cannot be applied to the form of clothing single-piece flow production. In order to make the template design suitable for garment single-piece flow production to form lean production and achieve efficient manufacturing, this large template must be split into multiple templates reasonably according to the standard work time of garment single-piece flow production mode. And then each template is assigned to the corresponding position and it is necessary to ensure that the pipeline can go smoothly. Instead, when completion time of a template process is less than the standard pace and the remaining work cannot be used to finish other working procedures, it should be considered how to make adjacent procedures reasonably be designed in a same template to make the work time of the station as close to the standard beat of the line as possible in redesigning templates. 


\section{GST analysis}

Standardization of garment work makes it possible to develop all possible action repository of operators in a production process of garment producing and sewing industry. It is called as General Sewing Time [7], referred to as "GST". GST is the premise of the actual time to achieve each station of the production assembly line consistent with the standard rhythm and the basis of ensuring a smooth line. Because the production model of clothing single-piece flow based on template technology has a higher requirements for process balance and synchronization of cycle time. So the analysis of GST is another important guarantee to achieve a more stable and higher efficiency garment single-piece flow.

Template fixture used in garment process production enables some process operations which are very complex and unable to be described by the basic actions to be completed by a series of continuous actions combined with some fundamental standard actions including dropping, catching, closing etc. This requires reanalysis of GST on the procedures of new operations. With the standard time for each station, it distributes the processes in accordance with the principles of same working procedure, similar working procedure and requiring special equipment to complete process harmonized, so that every station is to be done with a series of continuous actions in between a series of procedures. Clothing singlepiece flow production mode based on template technology realizes the standardization of apparel operations, which forms GST to provide the basis of lean production for the arrangement of the garment production line and the distribution of working procedure, so that the production mode can obtain the more output with the less input.

\section{E. Man-machine station arrangement}

The idea of lean production requires that the arrangement of the station should reduce the floating actions of the staff as few as possible, and the front and rear work stations should be ensured in the state of smooth connection [8]. For example, the position that basic ending movements from the previous station of making the garment piece placed in the flow transfer box is just at the beginning of the basic movements of the next station, which avoiding unnecessary waste of some movements of searching and turning pieces over etc. The arrangement of the station should also take shortening the operating distance into consideration, including elements of the distance between the station and transfer box, item location place, nurturing good habits of employees, optimized design of operating table etc. When a process requires special equipment to complete and the completion of the time required is much less than the beat, the station can be equipped with two sets of equipment. But the respective completed process of the two sets is better to have one that can complete the process independently outside of line. So a line outside process can be formed in the assembly line, which can reduce waste of personnel and cost of production. Meanwhile such distribution can reduce the waste of actions caused by the shift of the station staff.

\section{F. Full participation consciousness}

The pattern of single-piece flow production based on template technology is not widely known as a new mode of production and is misunderstood by many skilled workers. In their eyes, the use of template technology has reduced the difficulty level of many processes. On the one hand companies no longer trust for their skills, and on the other hand their salaries would be affected. Therefore, it is necessary to change the mistake of thinking of the employee, especially of firstline operators of production workshop. They need to be told to use the production mode within the same time, although difficulties of the completed process has reduced, the numbers completed in phase time are far more than those in traditional form of single-pieces flow production, and total performance salary lines of number multiplied by single pieces also will be far more than those of traditional form of single-piece flow operations.

\section{CONCLUSIONS}

In a word, garment single-piece flow production based on template technology reduces the level of skill required for front-line workers greatly and guarantee the quality of products. Meanwhile, this mode makes production site and operation of clothing enterprise more standardized. Compared with the traditional production operation of single piece flow, single-piece flow production based on template technology has saved a lot of working procedure effectively in process analysis, and greatly reduced production time, and made production line more stable and efficient. Therefore, less bottleneck process caused by operating difficulties, and the solution of eliminating bottleneck process is not dependent on skilled turners or increasing stations, but through redistribution and readjustment between several station processes. Garment single-piece flow production based on template technology makes garment manufacturing develop towards automation and intelligence, using intelligence to form lean production and create flexible production, which is in line with international 4.0 industrial concept and requirements of manufacturing in China 2025.

\section{ACKNOWLEDGMENT}

This work is partially supported by Planning Project of Suzhou Municipal Science and Technology Bureau(NO.). The authors wish to thank the useful comments of Kesheng Wang and the anonymous reviewers to this paper.

\section{REFERENCES}

[1] Z.B Zhang, P. Li, P.Z Wen. "Research on the application of intelligent garment template in the perspective of Industrial Engineering," Wool Textile Journal, China, vol.2, pp.68-71, April 2016.

[2] Y Wang, H.Z. Zhang, X.Y. Wang. "Application of Single Piece Flow of Handle Double Row Straight Line Type in Clothing Enterprises," Knitting Industries, vol. 1, pp.74-77, January 2016

[3] Y.C Zhang, G. Xu, J. Qing, etc.. "Application and development of template technology in the production of apparel industry," China textile leader, vol. 9, pp.71-73, September 2014. 
[4] H.L. Zhang, "Automatic garment template technology," Journal of Harbin Vocational \& Technical College, vol.1, pp.169-170, January 2014.

[5] X.L Shen, "Discussion on organization and management of garment production based on one-piece flow," Shanghai Textile Science and Technology, vol.5, pp.61-63, May 2013.

[6] Y. Wang, Q. Yu, and K.S. Wang, "Extracting associative rules from RFID data." International Joint Conference on e-Business and Telecommunications, Germany: Springer, 2013.
[7] X.F. Zheng, "The development and practice of clothing unit synchronous production system," Shanghai Textile Science and Technology, vol.6, pp.16-18, June 2011.

[8] Y.C. Chen, C. Du, A.H. Zhong, "Using lean production to solve the waste phenomenon of garment enterprises," Journal of Wuhan Textile University, vol.2, pp.17-19, February 2011. 